\title{
EMG responses to free fall in elderly subjects and akinetic rigid patients
}

\author{
A R Bisdorff, A M Bronstein, C Wolsley, M A Gresty, A Davies, A Young
}

Hôpital de la Ville, Esch-sur-Alzette, Luxembourg A R Bisdorff

\section{MRC Human}

Movement and

Balance Unit, National Hospital for Neurology and Neurosurgery, Queen Square, London, UK

A R Bisdorff

A M Bronstein

C Wolsley

M A Gresty

University

Department of

Geriatric Medicine,

Royal Free Hospital,

London UK

A Davies

A Young

Correspondence to:

Dr AM Bronstein, MRC

Human Movement and

Balance Unit, National

Hospital for Neurology and

Neurosurgery, Queen

Square, London, WC1N

3BG, UK.

Received 2 july 1998 and in revised form

12 October 1998

Accepted 16 October 1998

\begin{abstract}
Objectives-The EMG startle response to free fall was studied in young and old normal subjects, patients with absent vestibular function, and patients with akineticrigid syndromes. The aim was to detect any derangement in this early phase of the "landing response" in patient groups with a tendency to fall. In normal subjects the characteristics of a voluntary muscle contraction (tibilais anterior) was also compared when evoked by a non-startling sound and by the free fall startle.
\end{abstract}

Methods-Subjects lay supine on a couch which was unexpectedly released into free fall. Latencies of multiple surface EMG recordings to the onset of free fall, detected by a head mounted linear accelerometer, were measured.

Results and conclusions-(1) EMG responses in younger normal subjects occurred at: sternomastoid 54 ms, abdominals $69 \mathrm{~ms}$, quadriceps $78 \mathrm{~ms}$, deltoid $80 \mathrm{~ms}$, and tibialis anterior $85 \mathrm{~ms}$. This pattern of muscle activation, which is not a simple rostrocaudal progression, may be temporally/spatially organised in the startle brainstem centres. (2) Voluntary tibialis EMG activation was earlier and stronger in response to a startling stimulus (fall) than in response to a nonstartling stimulus (sound). This suggests that the startle response can be regarded as a reticular mechanism enhancing motor responsiveness. (3) Elderly subjects showed similar activation sequences but delayed by about $20 \mathrm{~ms}$. This delay is more than can be accounted for by slowing of central and peripheral motor conduction, therefore suggesting age dependent delay in central processing. (4) Avestibular patients had normal latencies indicating that the free fall startle can be elicited by non-vestibular inputs. (5) Latencies in patients with idiopathic Parkinson's disease were normal whereas responses were earlier in patients with multiple system atrophy (MSA) and delayed or absent in patients with Steele-RichardsonOlszewski (SRO) syndrome. The findings in this patient group suggest: (1) lack of dopaminergic influence on the timing of the startle response, (2) concurrent cerebellar involvement in MSA may cause startle disinhibition, and (3) extensive reticular damage in SRO severely interferes with the response to free fall. (F Neurol Neurosurg Psychiatry 1999;66:447-455)

Keywords: startle; falls; akinesia
Fall related injuries are common clinical problems. ${ }^{1}$ In patients with neurological disease and in elderly people the issue is particularly important because falls can lead to severe disability or death. ${ }^{2}$ Although several deficits in postural responses in elderly people and akinetic-rigid syndromes are recognised, ${ }^{345}$ it is less clear what neuromuscular events are actually triggered by a fall. Indeed, for a person in the middle of a fall it is more important to be able to "land" safely than to avoid a future fall.

In cats, ${ }^{6}$ monkeys, ${ }^{7}$ and to some extent humans, ${ }^{8}$ the "landing" response depends at least partly on vestibular function. The nature of the response is not entirely clear, however. Adapting a technique initially described by Halmagyi and Gresty ${ }^{9}$ to study blink responses during a limited free fall, we compared EMG responses from cranial muscles in response to free fall and to an acoustic startling stimulus. ${ }^{10}$ It was found that the sequence of activation and absolute latencies to both stimuli were the same. This suggested that the early response detected during free fall was a "startle" and not necessarily a specific vestibulospinal response, a view that was reinforced by the finding that the cranial latencies found in an alabyrinthine subject were only marginally different from those of normal subjects.

In the present paper we examined responses to free fall in a sample of young and old normal subjects, three patients with absent vestibular function, and in patients with akinetic-rigid syndromes: Parkinson's disease (PD), SteeleRichardson-Olszewski syndrome (SRO), and multiple system atrophy (MSA). The work aimed to investigate further the nature of the early free fall response in the body musculature and whether the response is deranged in normal elderly people and in neurological diseases with increased risk of falls. This work has partly appeared in a conference proceedings. ${ }^{11}$ In addition, an experiment was conducted to assess a possible role of free fall startle in the preparation of voluntary movement.

\section{Methods}

NORMAL SUBJECTS

A group of 32 normal volunteers, 12 women and 20 men, mean age 34.9 (SD 9.5) (range 21-57) years, and a group of 17 healthy elderly subjects, 12 women and five men, mean age 74.9 (SD 3.3) (range 70-80) years, were investigated. The elderly subjects were selected for having no relevant medical history; exclusion criteria were overt cerebrovascular or other neurological disease, history of hypertension, cardiac, or metabolic disease, and drug use including sedatives. All had normal results in 


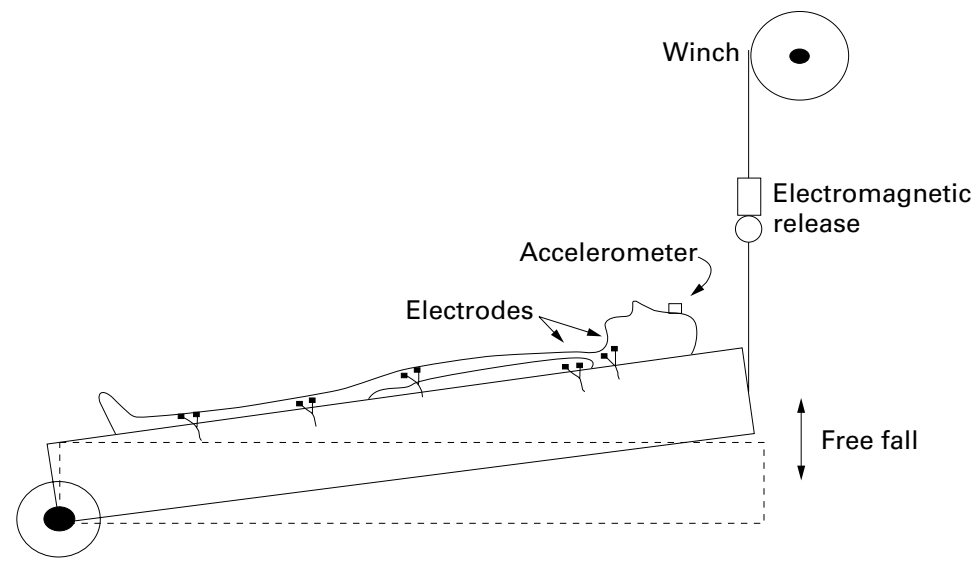

Figure 1 Schematic drawing of the experimental set up.

neuro-otological investigations including eye movement and rotational tests and normal postural reflexes on clinical examination.

PATIENTS WITH LABYRINTHINE DEFECTS

Three patients with bilateral absence of vestibular function were tested. One was a 39 year old woman with bilateral section of the VIII (cochleovestibular) nerve because of neurofibromatosis type II. The second patient was a 30 year old man who acquired deafness and loss of vestibular function during a meningitis as a child without any other sequelae. Patient 3 was a 30 year old man with idiopathic loss of vestibular function, ${ }^{12}$ after repeated vertiginous attacks. In all cases, the absence of vestibular function was defined as no nystagmic response to horizontal angular velocity steps of $\pm 80 \%$ s and to caloric irrigation at $30^{\circ} \mathrm{C}$ and $44^{\circ} \mathrm{C}$, in the absence of optic fixation.

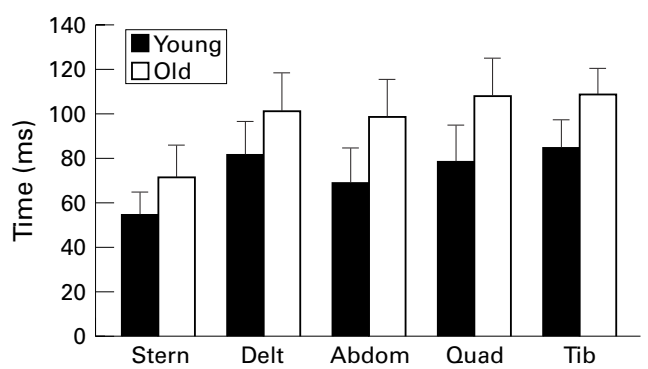

Figure 3 Summary of mean (SD) normal young $(n=32)$ and old subject $(n=17)$ data showing the preserved activation sequence but significant delay for all muscles ( $t$ test, $p<0.001$ ).

PARKINSONIAN SYNDROMES

Patients with advanced stages of parkinsonian syndromes (Hoehn and Yahr stages III and IV) were investigated. They all had variable degrees of impairment of postural reflexes during clinical examination. Eight had the diagnosis of idiopathic PD (two women six men, aged 48.4 (SD 11.6) (range 33-66) years), eight had MSA (two women, six men, aged 57.9 (SD 9.0) (range 44-67) years) and eight SRO (two women, six men, aged 60.3 (SD 5.0) (range 55-70) years. Diagnostic criteria used were as defined in Wenning et al ${ }^{13}$ and Litvan et al. ${ }^{14}$ All subjects involved in the study gave informed consent (through a competent legal guardian in one patient with dementia) to the procedures, which had been reviewed and approved by the ethics committee of the National Hospital and Institute of Neurology.

MAIN EXPERIMENT (STARTLE RESPONSE)

For the main experiment (young $v$ old; normal controls $v$ patients) subjects lay supine on a couch which rotates about a horizontal axis placed at the foot end (fig 1). The couch was lifted with an electric winch to a $10^{\circ}$ head up

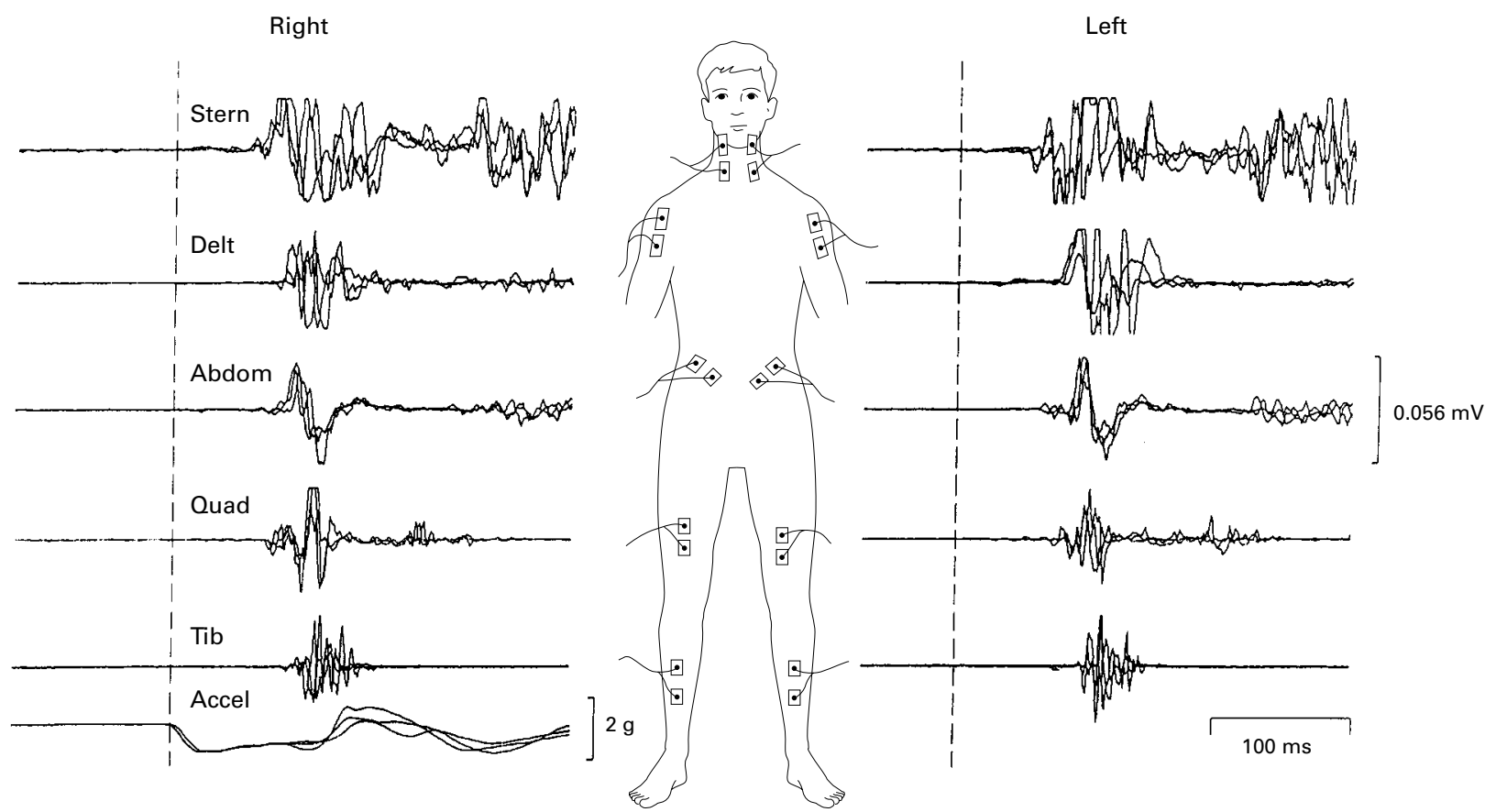

Figure 2 Overlay of three EMG records of a 25 year old woman showing sequential activation of sternomastoid, abdominals, deltoids, quadriceps, and tibialis anterior muscles. 


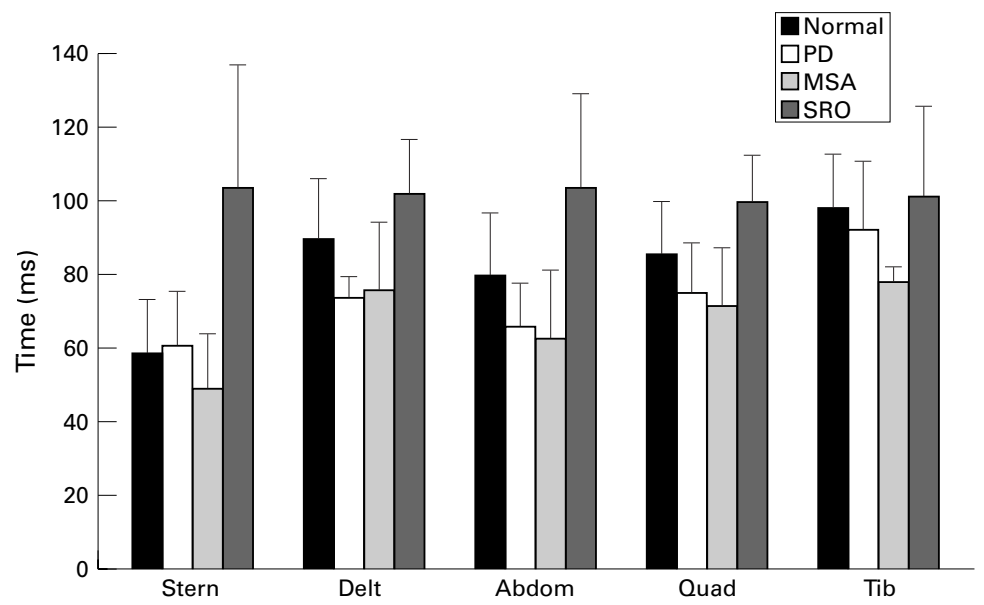

Figure 4 Latencies to EMG onset in different akinetic rigid syndromes compared with an aged matched group of normal subjects. Patients with PD were not different from normal, in SRO syndrome latencies were significantly delayed for sternomastoids and abdominals and in MSA the latency to tibialis anterior was significantly shortened ( $t$ test, $p<0.01$ ).

tilted position; the subjects' eyes were closed. Surface electrodes were placed bilaterally on sternomastoid, deltoid, abdominal (dorsal 9 level), quadriceps, and tibialis anterior muscles. A precision linear accelerometer was tightly taped to the forehead. An electromagnetic release allowed the head end of the couch to drop suddenly from the $10^{\circ}$ head up tilt. The free fall was gently braked as the couch passed through horizontal by heavy duty rubber bands (bungees) allowing a fall duration of 300-350 ms. The couch was unexpectedly released into free fall 6-10 times at irregular intervals lasting 1-3 minutes. EMG signals were bandpass filtered $(32 \mathrm{~Hz}-3200 \mathrm{~Hz})$ and digitised at 1000 $\mathrm{Hz}$. Data acquisition was triggered by the electromagnetic release with a $100 \mathrm{~ms}$ pretrigger and $400 \mathrm{~ms}$ post-trigger sampling time. The variable measured is the onset of EMG activity for the different muscles reported from the onset of the accelerometer signal. An additional experiment for a patient with SRO is described in the results section.

\section{COMPLEMENTARY EXPERIMENT (VOLUNTARY} REACTION TIME)

A voluntary reaction time experiment was devised to investigate the role of the free fall induced startle in the preparation of voluntary movement. Subjects lay on the couch with surface EMG electrodes on the left tibialis ante-

SRO Patient

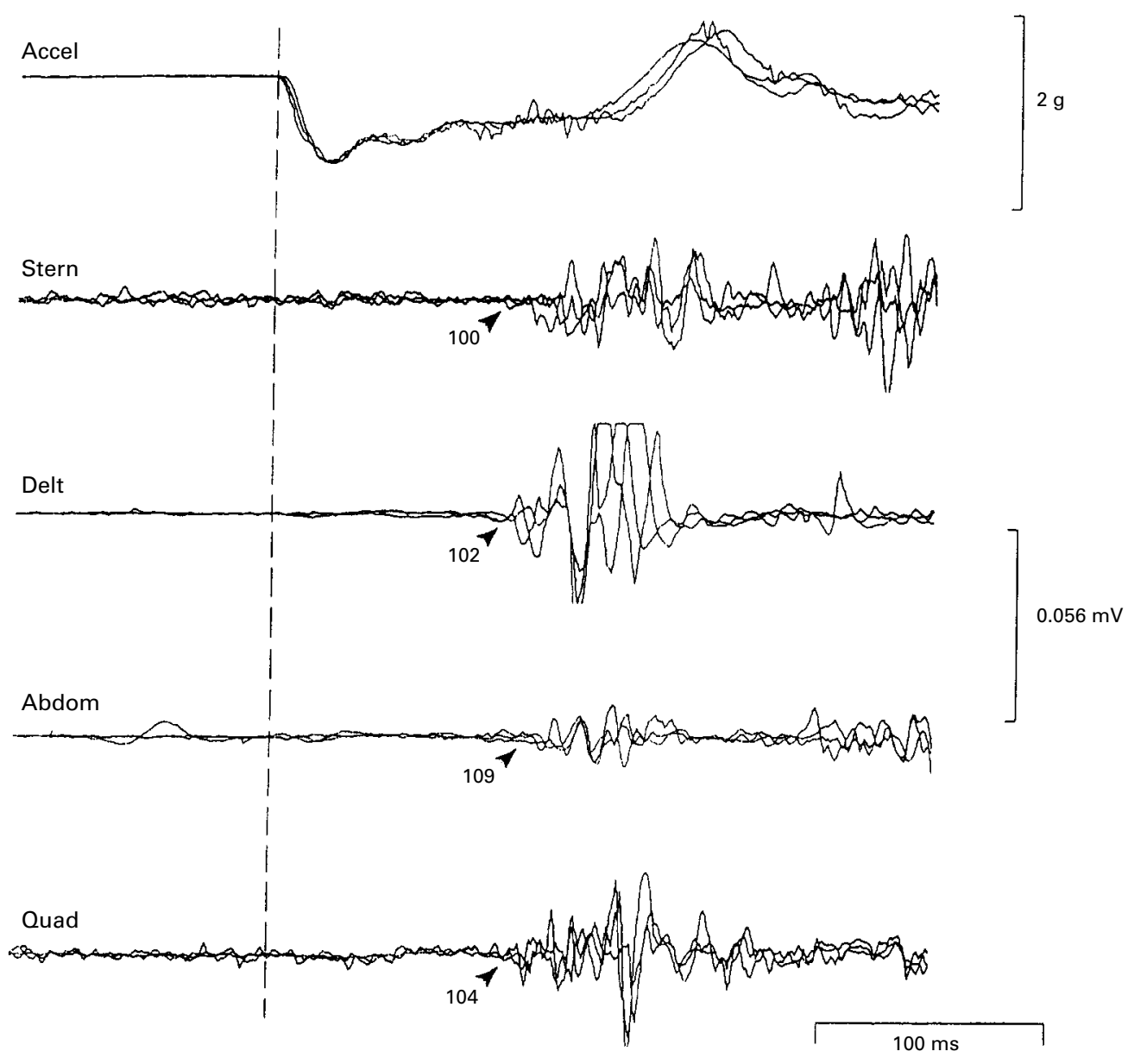

Figure 5 Overlay of three traces in a patient with SRO showing the delayed responses, particularly in the sternomastoid, and the different activation sequence compared with normal subjects (see figs 1 and 2 for comparison with normal responses). 


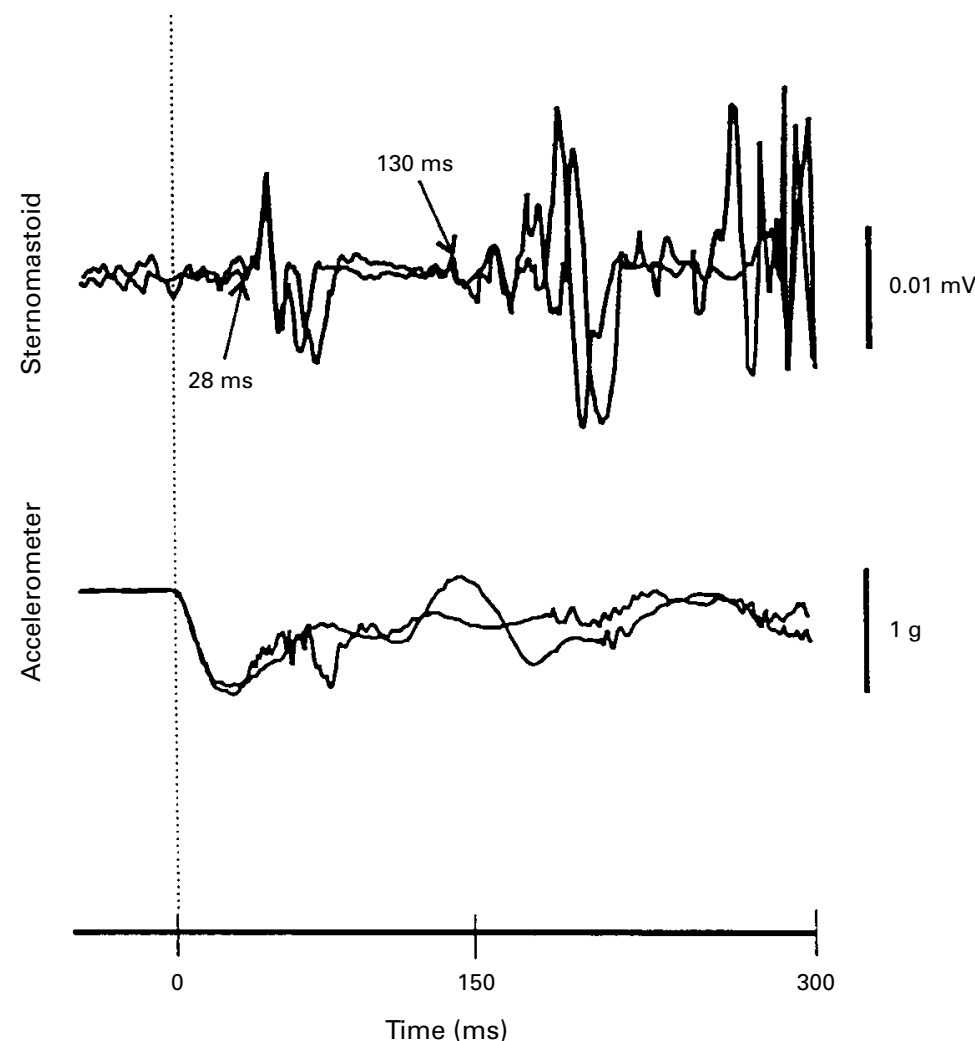

Figure 6 Sternomastoid recordings in the whole body drop in a patient with SRO with neck turns during walking. An early component (28 ms) separate from the startle response (130 ms) is seen. muscle activation was preserved in the elderly group but absolute latencies were prolonged by about $20 \mathrm{~ms}$ depending on the individual muscle (fig 3). The differences in latencies between the two groups were statistically significant for each muscle ( $t$ test, $\mathrm{p}<0.001)$.

Subjects with labyrinthine defects

All EMG responses in the three alabyrinthine patients tested were within the normal limits shown in fig 3. Latency values for patient 1 were sternomastoid $69 \mathrm{~ms}$, deltoid $98 \mathrm{~ms}$, abdominal $88 \mathrm{~ms}$, tibialis $103 \mathrm{~ms}$. The quadriceps latency was not recorded. Instead, in this patient cranial muscle responses were recorded, reported normal in Bisdorff $e t$ al ${ }^{10}$; for patient 2 sternomastoid was $50 \mathrm{~ms}$, deltoid 83 ms, abdominal $65 \mathrm{~ms}$, quadriceps $83 \mathrm{~ms}$, and tibialis $80 \mathrm{~ms}$, and for patient 3 the sternomastoid was $36 \mathrm{~ms}$, deltoid $55 \mathrm{~ms}$, abdominal 55 $\mathrm{ms}$, quadriceps $61 \mathrm{~ms}$, and tibialis $80 \mathrm{~ms}$.

\section{Akinetic rigid syndromes}

To compare the results of these patients with a normal control group of a similar age, normal subjects younger than 36 and older than 75 years old were excluded. This yielded a control group of 24 normal subjects with a mean age of 54.1 (SD 15.4) years. Response asymmetries were not found and therefore responses from the two sides were collapsed.

A summary of the results in these patients is shown in fig 4. Patients with idiopathic PD had normal activation sequence and absolute latencies. The patients with MSA showed a trend towards shorter latency but with a preserved pattern of activation. By contrast, there were significant delays in muscle activation, particularly in the sternomastoids in patients with SRO, resulting in the loss of the normal pattern of activation (figs 4 and 5). A further 73 year old male patient with SRO had no detectable responses and therefore his data were neither included in fig 4 nor in the statistics.

An analysis of variance (ANOVA) (subject group by muscle) showed significant effects (subject group, $F=28.9$, p $<0.0001$; muscle, $F=10.8$, p $<0.0001)$. There was a significant interaction between these two variables $(F=1.9$, $\mathrm{p}=0.03$ ) indicative of a different latency pattern in the different subject groups. This interaction disappeared $(p=0.52)$ if the data from the SRO group were not included; this indicates that the latency pattern in the SRO group did not follow the trend found in the other groups (normal, PD, and MSA, fig 4). Multiple comparisons with the $t$ test in the five muscles examined were performed with significance levels adjusted by a Bonferroni correction to $p<0.01$. These showed significantly prolonged latencies of the sternomastoid and the abdominal muscles in SRO as well as significantly shorter latencies in the tibialis anterior in MSA. The other muscles in the PSP and MSA groups followed a similar trend (fig 4) but did not quite reach significance at $\mathrm{p}<0.01$.

A special pattern of response was found in two patients with SRO with an unusual neck twisting during walking. ${ }^{15}$ The neck twisting occurred in the opposite direction to body turns and these 


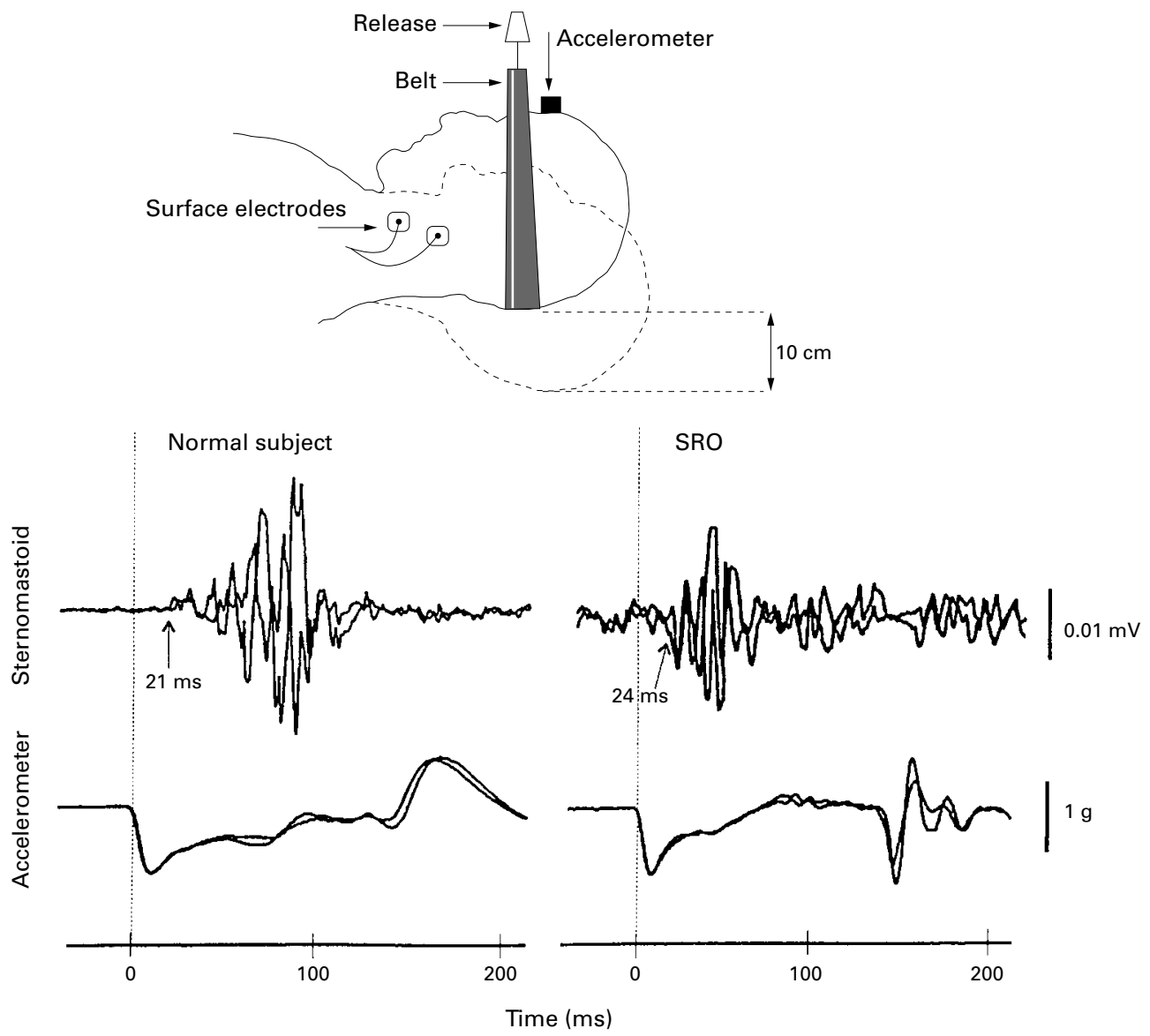

Figure 7 Comparison of the vestibulocollic reflex triggered by an isolated head drop in the patient with SRO shown in fig 5. Note the comparable latency in a normal subject. The technique used (Ito et al ${ }^{17}$ ) is schematically shown at the top.

patients therefore had difficulty in facing the direction of heading while walking. Such neck turns are thought to be due to the action of unopposed vestibulocollic reflexes which tend to stabilise the head in space. ${ }^{16}$ Figure 6 shows the free fall response in one of these patients, with an unusually short activation of the sternomastoid at $28 \mathrm{~ms}$ (normal mean about $60 \mathrm{~ms}$, fig 4 ). This latency is in the range of both the vestibulocollic reflex described in a patient with SRO with neck twisting $^{16}$ and the vestibulocollic short latency response which can be elicited in normal subjects by selective head drop. ${ }^{17}$ Figure 7 (top) (courtesy of Drs S Corna and Y Ito) illustrates the technique to elicit the short latency sternomastoid response, essentially a sudden "drop of the head". Figure 7 (bottom) presents data from the patient with SRO tested with the head drop technique, showing sternomastoid activation at $24 \mathrm{~ms}$, in the range of the short latency described for this vestibulocollic response. ${ }^{17} 18$ We concluded that these two patients with SRO with neck twisting and early sternomasoid EMG during the whole body free fall experiment have an early vestibulospinal response and a delayed free fall startle reaction. The early components in these two patients were not included in the calculations for the free fall startle.

COMPLEMENTARY EXPERIMENT (VOLUNTARY REACTION TIME)

Figures 8 and 9 show individual, rectified EMG recordings in two normal subjects in response to randomly presented startling stimulus (fall) or non-startling stimulus (click). The subject's task was to dorsiflex the ankles in response to either stimuli. The fall induced startle occurred at about $100 \mathrm{~ms}$ (arrow) followed by the voluntary contraction at about $200 \mathrm{~ms}$ (left of figs 8 and 9). Note that there was little variability of latency and amplitude in the voluntary contractions in response to the free fall, from trial to trial. By contrast, during the voluntary contraction in response to the click there was considerable variability in both amplitude (fig 8 right) and latency (fig 9 right). Mean and median reaction times were shorter during the startling stimulus than during the click (fig 10), ( $t$ test, $\mathrm{p}<0.0001$ ). However, if only the shortest latency was considered in each subject then there was no statistical difference between the reaction time to the startling and non startling stimuli (fall $=181.3$ (SD 43.0) ms; auditory=185.3 (SD 54.5) ms). Across subjects, the latency of the involuntary fall induced startle response was correlated with the latency of the voluntary response to the fall stimulus $(r=0.426 \mathrm{p}=0.0008)$.

To assess the relative strength of the response the rectified EMG areas were normalised in individual subjects by setting the strongest single activation found at an arbitrary level of $100 \%$. The mean EMG strength was significantly larger in response to the startling stimulus (fall=78.6 (SD 17.2)) than to the non- 

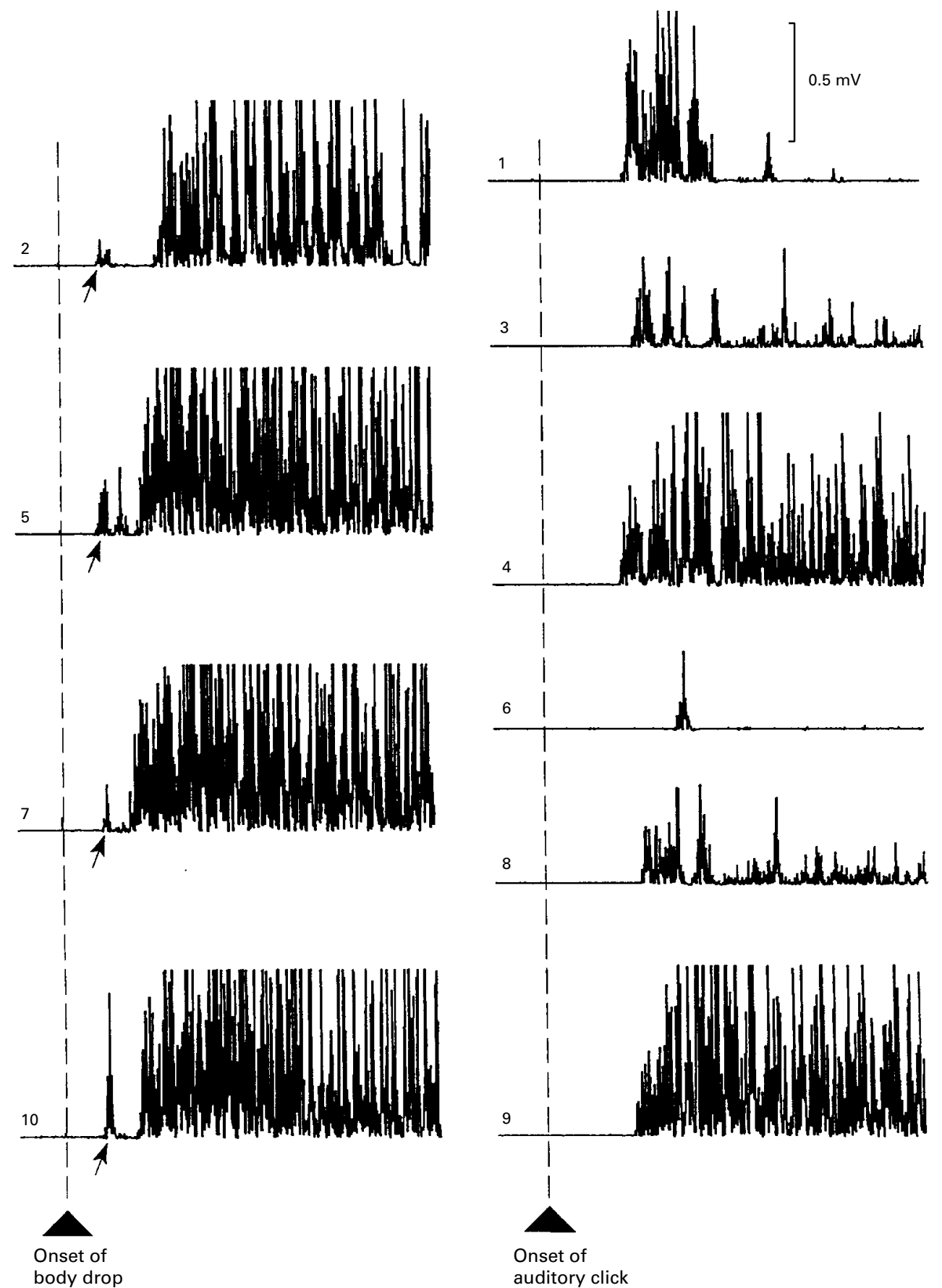

$500 \mathrm{~ms}$

$500 \mathrm{~ms}$

Figure 8 Simple reaction task experiment with a normal subject asked to quickly dorsiflex the feet in reaction to either the startling fall (left) or a non-startling auditory click (right) presented in random order. The numbers show the order of stimulus presentation. The response was more consistent for activation strength after the fall than after the auditory stimulus. The arrows indicate the startle induced by the fall, at latencies of about $100 \mathrm{~ms}$.

startling stimulus (click=50.4 (SD 18.5); arbitrary \% EMG units; $\mathrm{p}=0.0001)$.

\section{Discussion}

FUNCTION AND ORGANISATION OF THE EMG RESPONSE TO FREE FALL

Free fall, even if controlled as in these experiments, is subjectively startling. Analysis of cranial nerve responses in an identical free fall experiment yielded similar EMG activation patterns to those obtained with a loud, startling sound. ${ }^{10}$ The generalised motor activation found in the current study therefore must be considered as a startle even though some EMG activity from vestibulospinal pathways cannot easily be ruled out. At least in the sternomastoid this seems unlikely as activation of vestibulospinal pathways by head fall induces a 


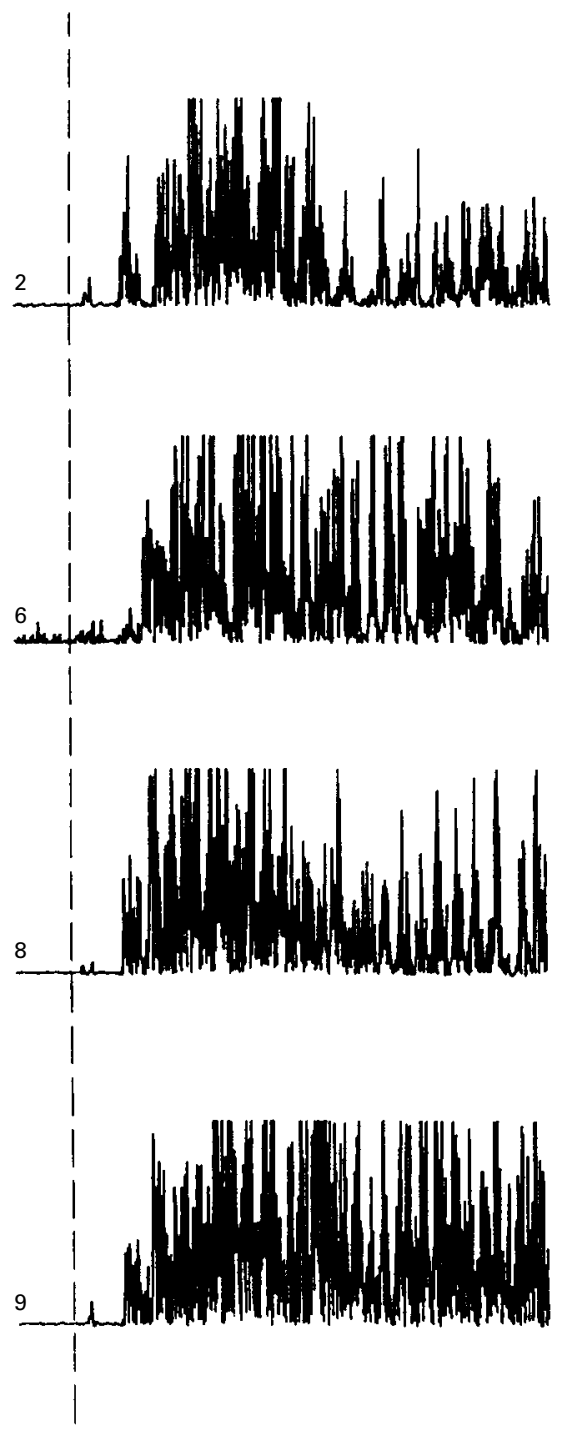

Onset of body drop
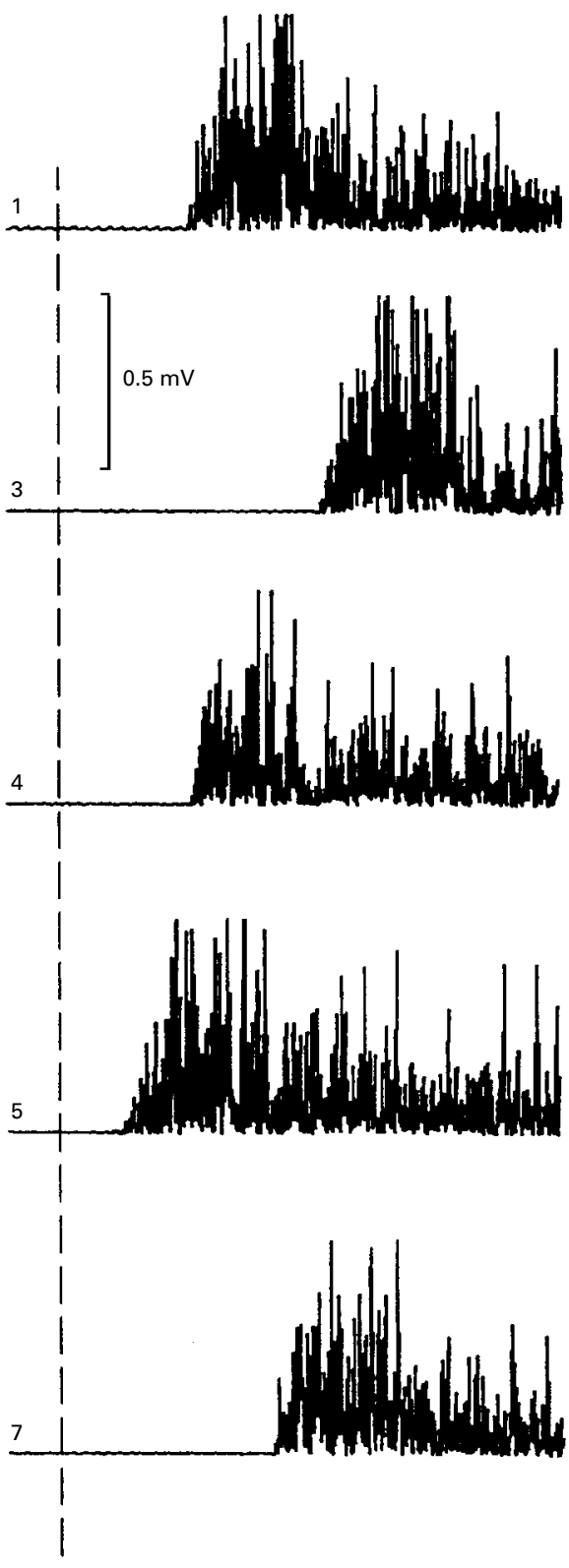

Onset of

auditory click

Figure 9 Same experimental arrangement as in fig 8. In this subject the response was more consistent for latency after the fall than after the click.

response at a shorter latency than those found here. ${ }^{17}{ }^{18} \mathrm{~A}$ further indication that the response does not correspond, in the main, to activation of specific vestibulospinal mechanisms comes from the finding that EMG patterns in the cranial $^{10}$ and skeletal muscles examined are preserved in patients with bilateral loss of vestibular function.

The origin and propagation of the neural signal responsible for the startle EMG pattern is still the subject of some debate. The results we obtained both in cranial and somatic muscles cannot be explained by a single descending volley from the brainstem as such a model would require a consistent rostrocaudal sequence of activation. Instead, our current data show that the innervation of thoracic myotomes (abdominal muscles) precedes cervical myotomes (deltoid) and that muscles as far apart as the deltoid and quadriceps are activated roughly at the same time. These data therefore favour the view that the EMG activa- 

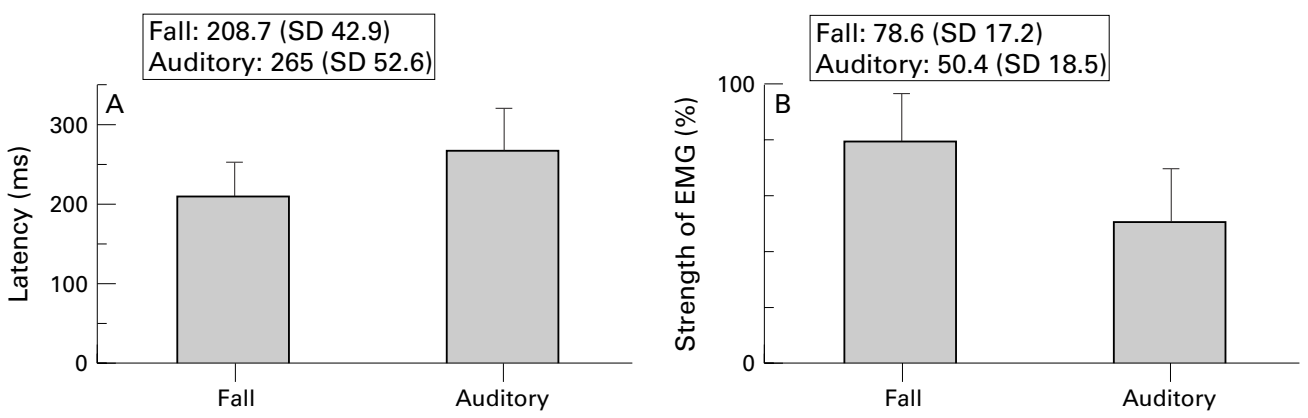

Figure 10 (A) Mean latencies for onset of EMG activity and (B) mean magnitude of voluntary EMG activity as a \% of maximum contraction in reaction to a free fall or to a non-startling auditory click. The mean (SD) for 12 normal subjects are shown.

tion found in the startle response is the result of different descending volleys generated in the pontomedullary centres. ${ }^{19} 20$ These centres would be capable of generating a startle in response to intense, unpredictable (startling) stimuli mediated by different sensory systems. In the case of a free fall it seems reasonable to assume that, in normal subjects, the vestibular system is important but, as the data suggest, patients with longstanding absence of vestibular function are capable of using other sensory sources to generate the response. Contact and proprioceptive signals, particularly from the neck, have access to the brainstem at latencies only fractionally longer than vestibular ones ${ }^{21}$ and could be important in detecting a fall and triggering motor responses.

Which specific function/s are subserved by the startle reaction is not entirely clear. ${ }^{22}$ The reaction time experiments presented in figs 8 and 9 aimed to consider this question, by investigating if the latency and strength of a voluntary motor reaction could be improved by a startling stimulus. It was found that mean reaction times were shorter and variability of the response was reduced after the startling stimulus. A similar picture emerged from the analysis of the strength of the response to the startling and non-startling stimuli. These results would therefore indicate that some functional advantage is present when a voluntary reaction is triggered by a startling stimulus. As startling stimuli would usually signal danger, it would be clearly beneficial to the subject to be able to respond strongly, quickly, and reliably.

In this study we chose to investigate the tibilalis anterior, a muscle normally involved in posture and locomotion. In a situation which threatens balance, postural muscles are under both reflex and voluntary control-for instance, during rescue reactions or in avoiding a visually detected obstacle. ${ }^{23}$ Our results suggest that the likelihood of a successful move is higher if such a response is initiated by a startle. Recently, work on a non-posturally relevant muscle investigated during acoustic startle reached similar conclusions. ${ }^{24}$ Although our experiments directly apply to voluntary responses triggered by a startle, it would be possible that postural motor programmes may also be augmented if triggered by a startling stimulus.
THE EMG REACTION TO FREE FALL IN HEALTHY ELDERLY SUBJECTS

The sequence of muscle activation was preserved in the healthy elderly group but the latencies were significantly delayed to all muscles. This suggests that with age the preset pattern of temporospatial organisation of the startle response is preserved. The magnitude of this latency delay cannot be explained by slowing of afferent or efferent age dependent conduction. All subjects had normal results on vestibular testing and had no overt long tract or peripheral nerve pathology. Age dependent slowing of central and peripheral motor conduction can only account for 3-5 ms of the delay in distal muscles. ${ }^{25}{ }^{26}$ This suggests that the major part of the delay occurs during central reticular processing. The age dependent slowing of saccades, ${ }^{27}$ also programmed in the reticular formation, is in agreement with our findings. The elderly subjects investigated here were in good health and had no history of falls. Nevertheless a delay in starting a reaction to prevent a fall or prepare for landing could contribute to the increased risk of falls and fall related injury with age.

\section{FREE FALL RESPONSES IN AKINETIC-RIGID} SYNDROMES

The main findings in the patients with parkinsonian symptoms were as follows. Patients with idiopathic PD were not significantly different from normal. Patients with SRO essentially lost the normal, patterned response and had delayed or even absent EMG responses. These delays reached significance in axial/proximal muscles, sternomastoid, and abdominal muscles. Patients with MSA had a preserved response pattern but with a tendency to shorter latencies. This reached significance in the tibialis anterior, the most distal muscle examined. These findings can be discussed in terms of the known pathological anatomy of these diseases.

Several clinical features of the SRO syndrome are related to the neuronal loss found in the reticular formation of the brainstem. The supranuclear gaze palsy is secondary to degeneration of neurons in the saccadic generators, located in the nuclei reticularis pontis oraliscaudalis, raphe interpositus, and rostral interstitial of the medial longitudinal fasciculus. ${ }^{28} 29$ It is also known from work in experimental 
animals that it is this area of the brainstem that is responsible for generating the startle response. $^{3031}$ The delayed and disorganised EMG reaction to free fall in these patients can be attributed to the loss of cells in this area of the brainstem as previously postulated ${ }^{19} 2032$ during investigations with the acoustic startle. The free fall stimulus in two of these patients with delayed startle was useful in disclosing an additional early vestibulocollic component at latencies of about $28 \mathrm{~ms}$. This early vestibulocollic response was corroborated with the "head drop" paradigm used to show such a response in normal subjects by Ito et al. ${ }^{17}{ }^{18}$ The presence of this early vestibulocollic component in some patients with SRO agrees with the recent finding of enhanced or unopposed vestibular induced head turns in some patients with SRO. ${ }^{15} 16$

The overall normality of the free fall startle in patients with PD is to be expected on the grounds that reticular nuclei are largely intact in this condition and that the patients were taking antiparkinsonian drugs. The $\mathrm{H}$ reflex, however, does seem to receive a dopaminergic modulatory effect mediated by the auditory startle. ${ }^{33}$ By contrast, the results in the patients with MSA were unexpected as patients had responses at shorter latencies, particularly in the tibialis anterior. If we assume that shorter latencies are a sign of disinhibition of the startle reflex, ${ }^{22}$ we would postulate that the concomitant cerebellar involvement in these patients is responsible for the shorter latencies. It has been reported that the chloralose jerk, a reflex response mediated through reticular centres involved in startle generation (such as the nucleus reticularis gigantocelularis), can be suppressed by anterior lobe cerebellar stimulation. ${ }^{34}$ Thus, loss of the cerebellar inhibitory influence on these reticularly mediated responses may be responsible for some latency shortening.

Financial support from the Ministere de l'Education Nationale de Luxembourg and the CEC Grant, Access to Large Scale Facilities (Human Capital and Mobility Program), is gratefully acknowledged. We are also grateful to Drs Y Ito and S Corna who participated in the experiment shown in fig 7 and to Dr P Brown for useful comments and references.

1 Waller JA. Injury in aged. Clinical and epidemiological implications. New York State Fournal of Medicine 1974;74:2200-8.

2 Eddy TP. Deaths from falls and fractures. Comparison of mortality in Scotland and United States with that in England and Wales. British fournal of Preventive and Social England and Wales. British

3 Overstall W, Exton-Smith AN, Imms FJ, Johnson AL. Falls in the elderly related to postural imbalance. $B M \mathcal{F}$ 1977;i:261-4.

4 Peterka RJ, Black FO. Age related changes in human posture control: sensory organization tests. I Vestibul Res 1990;1:73-85.

5 Horak FB, Nutt JG, Nashner LM. Postural inflexibility in parkinsonian patients. $\mathcal{F}$ Neurol Sci 1992;111:46-58.

6 Watt DGD. Responses of cats to sudden falls: an otholith-originating reflex assisting landing. 7 Neurophysiol 1976;39:257-65
7 Lacour M, Xerri C, Hugon M. Compensation of postural reactions to fall in the vestibular neurectomized monkey. Role of the remaining
Res 1979;37:563-80.

8 Greenwood R, Hopkins A. Muscle responses to sudden free fall in man. $\mathcal{F}$ Physiol (Lond) 1976;254:507-18.

9 Halmagyi GM, Gresty M. Eye blink reflexes to sudden free falls: a clinical test of otolith function. $\mathcal{F}$ Neurol Neurosurg Psychiatry 1983;46:844-47.

10 Bisdorff AR, Bronstein AM, Gresty MA. Responses in neck and facial muscles to sudden free fall and a startling auditory stimulus. Electroencephalogr Clin Neurophysiol 1994;93: $409-16$

11 Bisdorff AR, Bronstein AM, Gresty MA, et al. EMG responses to sudden onset free fall. Acta Otolaryngol (Stockh) 1995;(suppl 520):347-9.

12 Rinne T, Bronstein AM, Rudge P, et al. Bilateral loss of vestibular function. Acta Otolaryngol (Stock) 1995;(suppl 520):247-50.

13 Wenning GK, Ben Shlomo Y, Magalhães M, et al. Clinical features and natural history of multiple system atrophy. An analysis of 100 cases. Brain 1994;117:835-45.

14 Litvan I, Agid Y, Calne D, et al. Clinical research criteria for the diagnosis of progressive supranuclear palsy (SteeleRichardson-Olszewski syndrome): report of the NINDSSPSP international workshop. Neurology 1996;47:1-9.

15 Bisdorff AR, Bronstein AM, Corna S, et al. Abnormal neck twisting during walking in progressive supranuclear palsy due to unopposed vestibulo-collic reflexes. Mov Disord 1997;12:270.

16 Bisdorff AR, Bronstein AM, Wolsley C, et al. Torticollis due to disinhibition of the vestibulo-collic reflex in a patient with Steele-Richardson-Olszewski syndrome. Mov Disord 1997;12:328-36.

17 Ito Y, Corna S, von Brevern M, et al. Neck muscle responses to abrupt free fall of the head: comparison of normal with labyrinthine-defective human subjects. F Physiol (Lond) 1995;489:911-6.

18 Ito $\mathrm{Y}$, Corna $\mathrm{S}$, von Breven $\mathrm{M}$, et al. The functional effectiveness of neck muscle reflexes for head-righting in response to sudden fall. Exp Brain Res 1997;117:226-72.

19 Brown P, Day BL, Thompson PD, et al. New observation on the auditory startle in man. Brain 1991;114:1891-902.

20 Brown P, Day BL, Rothwell JC, et al. The effect of posture on the normal and pathological auditory startle reflex. $f$ Neurol Neurosurg Psychiatry 1991;54:892-7.

21 Hikosaka O, Maeda M. Cervical effects on abducens neurons and their interaction with the vestibulo-ocular reflex. Exp Brain Res 1973;18:512-30.

22 Matsumoto J, Hallett M. Startle syndromes. In: Marsden CD, Fahn S. Movement disorders. 3rd ed. Oxford: Butterworth Heinemann, 1994:418-33.

23 Patla AE. Neurobiomechanical bases for the control of human locomotion. In: Bronstein AM, Brandt Th, Woollacott M, eds. Clinical disorders of balance, posture, and gait. London: Arnold, 1996;19-40.

24 Valls-Sole J, Sole A, Vallderiola F, et al. Reaction time and acoustic startle in normal human subjects. Neurosci Lett 1995; 195:97-100.

25 Claus D. Central motor conduction: method and normal results. Muscle Nerve 1990;13:1125-32.

26 Dorfman LJ, Bosley TM. Age-related changes in peripheral and central nerve conduction in man. Neurology 1979;29: $38-44$.

27 Wilson SJ, Glue P, Ball D, et al. Saccadic eye movement parameters in normal subjects. Electroencephalogr Clin Neurophysiol 1993;86:69-74.

28 Steele JC, Richardson JC, Olszewski J. Progressive supranuclear palsy. Arch Neurol 1964;10:333-59.

29 Revesz T, Sangha H, Daniel SE. The nucleus raphe interpositus in Steele-Richardson-Olszewski syndrome (progressive supranuclear palsy). Brain 1996;119:1137-43.

30 Leitner DS, Powers AS, Hoffman HS. The neural substrate of the startle response. Physiol Behav 1980;25:291-7.

31 Davis $M$, Gendelman DS, Tischler $\mathrm{MD}$, et al. A primary acoustic startle circuit: lesion and stimulation studies. $\mathcal{F}$ Neurosci 1982;2:791-805.

32 Vidailhet M, Rothwell JC, Thompson PD, et al. The auditory startle response in the Steele-RichardsonOlszewski syndrome and Parkinson's disease. Brain 1992; 115:1181-92.

33 Delwaide PJ, Pepin JL, Maertens de Noordhout A. The audiospinal reaction in parkinsonian patients reflects functional changes in reticular nuclei. Ann Neurol 1993;33:639.

34 Stenhouse D. Suppression of chloralose jerk responses by stimulation of the anterior lobe of the cerebellum. Brain Research 1970;17:148-52. 